\title{
Intravascular Near-Infrared Spectroscopy: A Possible Tool for Optimizing the Management of Carotid Artery Disease
}

\author{
Martin Horváth, MD ${ }^{1}$ Petr Hájek, MD, PhD ${ }^{1}$ Cyril Štěchovský, MD ${ }^{1} \quad$ Jakub Honěk, MD ${ }^{1}$ \\ Josef Veselka, MD, $\mathrm{PhD}^{1}$ \\ ${ }^{1}$ Department of Cardiology, Charles University in Prague, 2nd Faculty \\ of Medicine and Motol University Hospital, Prague, Czech Republic \\ Int J Angiol 2015;24:198-204. \\ Address for correspondence Josef Veselka, MD, PhD, Department of \\ Cardiology, Motol University Hospital, V Úvalu 84, 150 06, Praha 5, \\ Czech Republic (e-mail: veselka.josef@seznam.cz).
}

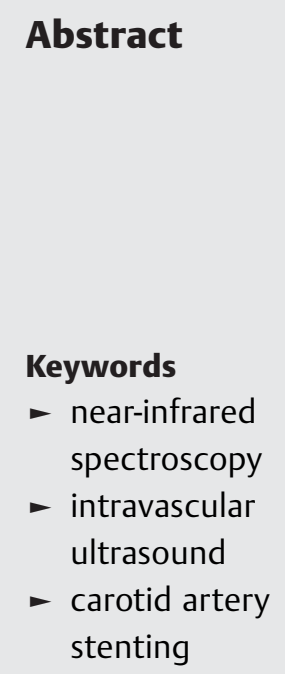

Stroke is the second most common cause of morbidity and mortality in the Western nations. It is estimated that approximately one-fifth of all strokes or transient ischemic attacks are caused by carotid artery disease. Thus, treatment of carotid artery disease as a mean of stroke prevention is extremely important. Since the introduction of carotid endarterectomy, debate has persisted over the treatment strategy for carotid artery disease. Current recommendations have many potential flaws because they are often based on older trials performed before the introduction of modern pharmacotherapy and are mostly based on the angiographic degree of stenosis, without an emphasis on the pathophysiology of the disease. Most carotid events are caused by rupture or distal embolization of the content of an unstable atherosclerotic plaque with a large lipid pool. Thus, it is plausible that the information regarding the composition of the atherosclerotic plaque could play an important role in deciding on a treatment strategy. In this review article, we provide information about near-infrared spectroscopy, a new invasive imaging modality, which seems to be capable of providing such information.
Ischemic stroke is a major public health issue because it is the most common cause of disability and the third leading cause of death in Western countries. ${ }^{1-3}$ It is estimated that atherosclerotic plaques in the internal carotid artery cause approximately 15 to $20 \%$ of all ischemic strokes. ${ }^{4}$ Because the disease is extremely debilitating, primary and secondary prevention is a deeply important topic. In the vast majority of cases, stenosis is caused by an atherosclerotic process., ${ }^{5,6}$ Our options in the management of the disease include a conservative approach, with optimal medication and carotid revascularization by either carotid endarterectomy (CEA) or carotid artery stenting (CAS). The guidelines for the management of carotid artery disease have mostly been based on clinical symptoms and the degree of stenosis. ${ }^{1,2}$ Many points regarding this issue remain controversial, partly because we currently do not have sufficient information about the composition of the plaque that causes the disease. With the introduction of modern imaging modalities, which are capable of providing such information, we might be able to optimize the management and tailor it more suitably to each patient according to the composition of the atherosclerotic plaque. Although noninvasive imaging methods will likely provide better solutions once they are capable of providing a powerful enough resolution, the new invasive imaging modality near-infrared spectroscopy (NIRS) seems to have great potential. As we can assume from the research conducted on coronary arteries, NIRS could have many useful applications in the management of carotid artery disease. It could help with the optimization of CAS by providing background for decisions about the embolic protection or stent used. It could also aid in the risk stratification of patients to CAS or CEA and with decision making in the treatment of asymptomatic patients. Herein, we provide background regarding this topic. 


\section{Current Evidence on Carotid Artery Disease}

Invasive treatment of carotid artery disease has been a wellrecognized form of stroke prevention for decades. The first CEA, performed in 1953, was followed by the first carotid angioplasty approximately three decades later. ${ }^{7-10}$ Much scientific evidence for the effectiveness of the respective approaches followed these milestones.

In the early 1990 s, the benefit of CEA over the contemporary standard medical therapy in symptomatic patients with greater than $50 \%$ carotid stenosis was confirmed by the first large, randomized, controlled trials: The North American Symptomatic Carotid Endarterectomy Trial (NASCET) and the European Carotid Surgery Trial (ECST). ${ }^{11,12}$ The Asymptomatic Carotid Atherosclerosis Study (ACAS) and the Asymptomatic Carotid Surgery Trial (ACST) subsequently provided background for the treatment of asymptomatic patients. ${ }^{13,14}$ The main limitation of all of these studies, despite highly recognized data, was that they were performed before the introduction of modern pharmacotherapy, such as statins or modern antihypertensives. ${ }^{15}$

CAS challenged CEA in the first randomized, controlled trials more than a decade later. At first, the Stenting and Angioplasty with Protection in Patients at High Risk for Endarterectomy (SAPHIRE) trial confirmed the noninferiority of CAS over CEA for symptomatic patients at increased risk for surgical complications. ${ }^{16}$

In the first trials, which included patients with an average surgical risk, CAS fared considerably worse. The Endarterectomy Versus Angioplasty in Patients with Severe Symptomatic Carotid Stenosis (EVA-3S) study had to be terminated prematurely because of a significantly higher incidence of 30day complications with CAS. ${ }^{17}$ In addition, the Stent-protected Percutaneous Angioplasty of the Carotid versus Endarterectomy (SPACE) trial failed to prove noninferiority of CAS compared with CEA for the periprocedural complication rate. ${ }^{18}$ The International Carotid Stenting Study (ICSS), which enrolled a large cohort of patients, documented statistically higher incidences of stroke, death, and periprocedural myocardial infarction (MI) in the CAS group than in the CEA group. ${ }^{19}$ However, all of the aforementioned trials were heavily criticized because of their flawed designs (i.e., the trials included physicians with only limited experience with CAS, and no embolic protection devices were required). ${ }^{20}$

The largest trial that compared CAS to CEA in patients at average surgical risk was the Stenting Versus Endarterectomy for Treatment of Carotid Artery Stenosis (CREST) study. This study, which was arguably the best-designed study, also yielded the most promising results with CAS thus far. The study included a total of 2,502 patients who were randomized to either CAS or CEA. At 2.5 years of follow-up, there was no significant difference $(7.2 \%$ vs. $6.8 \%, p=0.51)$ in the estimated 4-year rates of the primary end point (a composite of stroke, MI or death from any causes during the periprocedural period [30 days] or any ipsilateral stroke). Importantly, although the incidence of the composite outcome was similar between the groups, there was a statistically significant difference between the incidence of minor stroke and MI.
Stroke was more frequent with CAS ( 4.1 vs. $2.3 \%, p=0.01$ ), and MI was more likely to appear after CEA (2.3vs. $1.1 \%$, $p=0.03)^{21}$

Despite such a long experience, the treatment of carotid artery disease remains a challenge and the prevention of complications is crucial, given the large population of patients affected. The new diagnostic method NIRS seems to have potential in the risk stratification of patients and in the improvement of complication rates, particularly in the reduction of distal embolization.

\section{Near-Infrared Spectroscopy}

Near-infrared spectroscopy is a modern intravascular diagnostic modality that was developed for the detection of the lipid content of atherosclerotic plaques. The technique has been used for decades in science and industry to determine the chemical composition of substances. The principle of the method is the different absorbances of electromagnetic radiation in the near-infrared spectrum (wavelengths from 800 to $2,500 \mathrm{~nm}$ ) based on the presence of various chemical bonds in substances. When the backscattered signal is analyzed, a characteristic map of absorbance is obtained. The map is typical of every substance, only as a "fingerprint."22

The idea that NIRS could be useful for the detection of cholesterol within atherosclerotic plaques is more than 20 years old, ${ }^{23}$ but it took many years before a catheter suitable for intravascular diagnostics was developed. In 2008, Gardner et al published a validation study that proved the efficacy of NIRS compared with histology as the gold standard. ${ }^{22}$ A receiver operating characteristic analysis of the results yielded an area under the curve value of 0.89 (95\% confidence interval, 0.76 $0.85)$, suggesting that the method was accurate in the detection of lipid cores. ${ }^{22}$ One year later, the safety and efficacy of the method were proved in vivo. ${ }^{24}$ Subsequently, the method received Food and Drug Administration (FDA) and Conformité Européenne (CE) approval for use in coronary arteries, triggering a boom of research in the field.

Today, a commercially produced catheter is available. The imaging device consists of the following three main parts: a dual modality 3.2 F imaging catheter that incorporates both NIRS and intravascular ultrasound (IVUS), a device for mechanical pullback and rotation of the catheter through a vessel and a console with which one can observe the results of both imaging modalities in real time in the catheterization laboratory (-Fig. 1).

The IVUS results of the examination are depicted on both a tomographic ultrasound image of the vessel and a longitudinal IVUS cross-section (-Fig. 2). Together with the NIRS results, the IVUS results provide us with a so-called true vessel characterization. From the IVUS image, we can learn about the anatomical structure of the vessel, including the dimensions of lumen and external elastic membrane, the degree of stenosis, and the plaque burden (-Fig. 2).

The NIRS data are presented as a chemogram. Every pixel of this rectangular color-coded probability map represents the probability of lipid presence at the given location. Low probabilities of lipids are depicted as red, while the other 


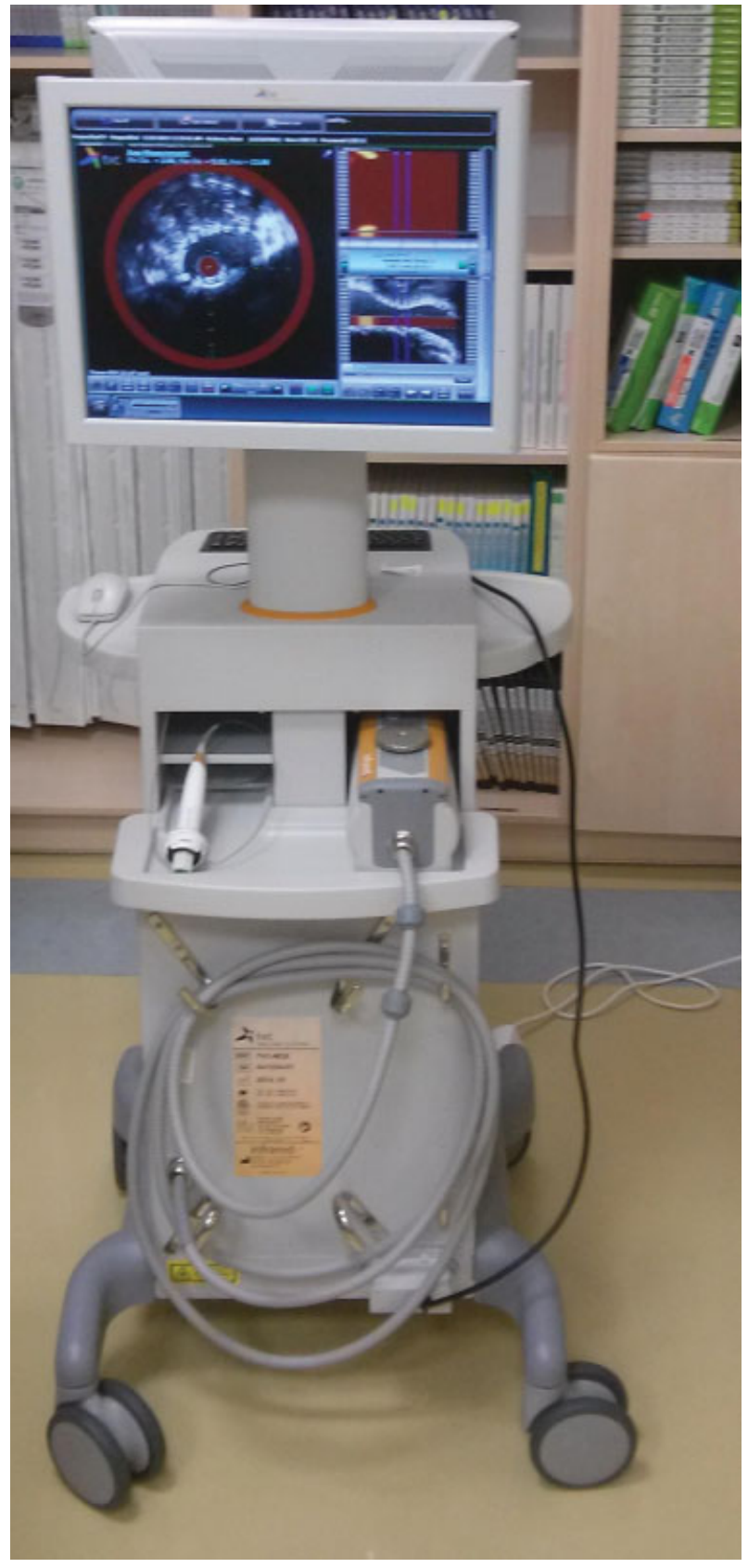

Fig. 1 The near infrared spectroscopy imaging device consisted of the following three main parts: a dual-modality $3.2 \mathrm{~F}$ imaging catheter that incorporates both near-infrared spectroscopy and intravascular ultrasound; a device for the mechanical pullback and rotation of the catheter through a vessel; and finally, a console with which one can observe the results of both imaging modalities in real time in the catheterization laboratory.

extreme of the scale is represented as yellow. The X-axis of the chemogram indicates the pullback position in millimeters, while the Y-axis represents the circumferential position in degrees, as though the coronary vessel has been incised along its longitudinal axis (-Fig. 3). ${ }^{25,26}$ The lipidcore burden index (LCBI) was established to satisfy the need for the quantification of the presence of lipids. The LCBI is defined as the proportion of yellow and red pixels on the

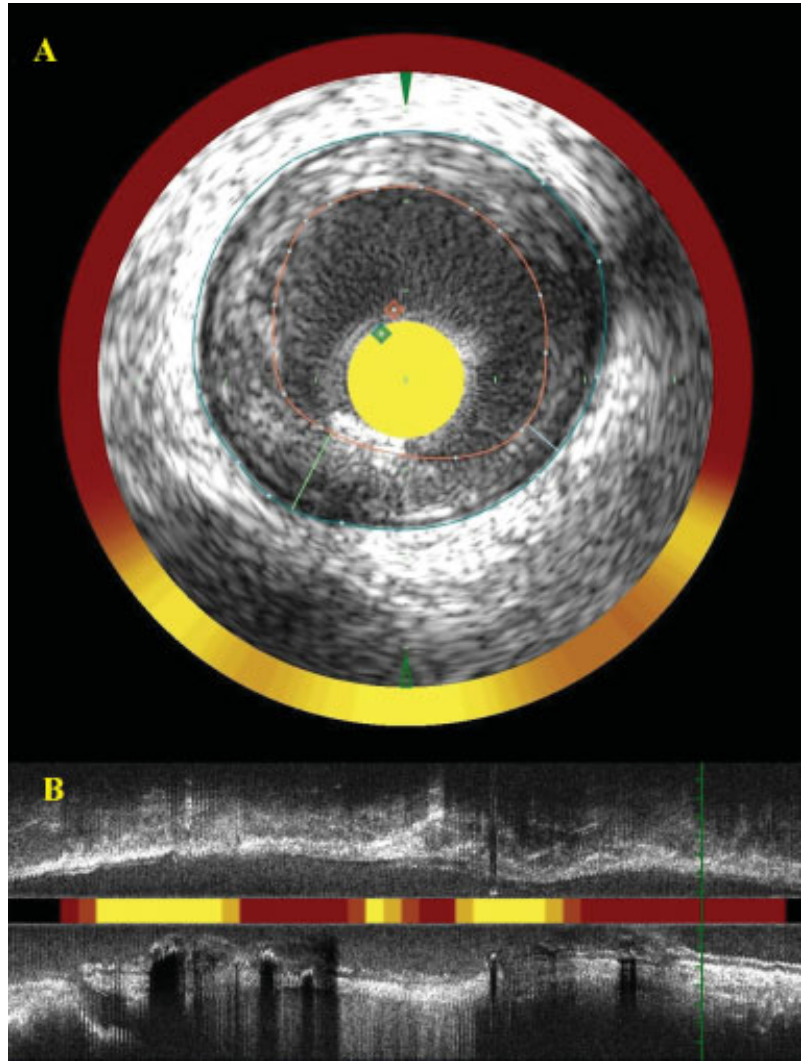

Fig. 2 The results of the intravascular ultrasound examination has two outputs. From the tomographic ultrasound image (panel A) of the vessel, we can learn about the anatomical structure of the vessel, including the dimensions of the lumen (red line) and the external elastic membrane (blue line). We can additionally calculate the lesion plaque burden as a fraction of the two parameters. The longitudinal intravascular ultrasound cross-section provides additional information about the lesion extent and severity (panel B).

chemogram multiplied by 1000 . The maximal LCBI per $4 \mathrm{~mm}$ describes the region with the highest lipid burden. ${ }^{22,25-27}$

\section{NIRS-IVUS for Optimizing CAS}

Despite more than three decades of experience with carotid interventions, there still seems to be much room for improving and fine tuning the procedure to prevent adverse events. ${ }^{9,16,17,20,21}$ Large prospective trials that compared CAS and CEA suggested that the higher incidence of stroke due to distal embolization is an important limitation of CAS, leading to worse outcomes of patients. ${ }^{17-19,21}$ It was demonstrated that new ischemic lesions could be detected by diffusion-weighted magnetic resonance imaging (MRI) more often after CAS than after CEA. ${ }^{28}$ Although the CREST trial did not find a significant difference in its primary end point, the incidence of minor stroke was higher in the CAS group, ${ }^{21}$ indicating a great area of improvement in CAS, which could theoretically drive its results even beyond those for CEA in a well-selected population of patients. This fact is why it is crucial to distinguish patients with a higher risk of periprocedural stroke and either to schedule them for CEA as a safer option or to tailor the CAS procedure accordingly, 


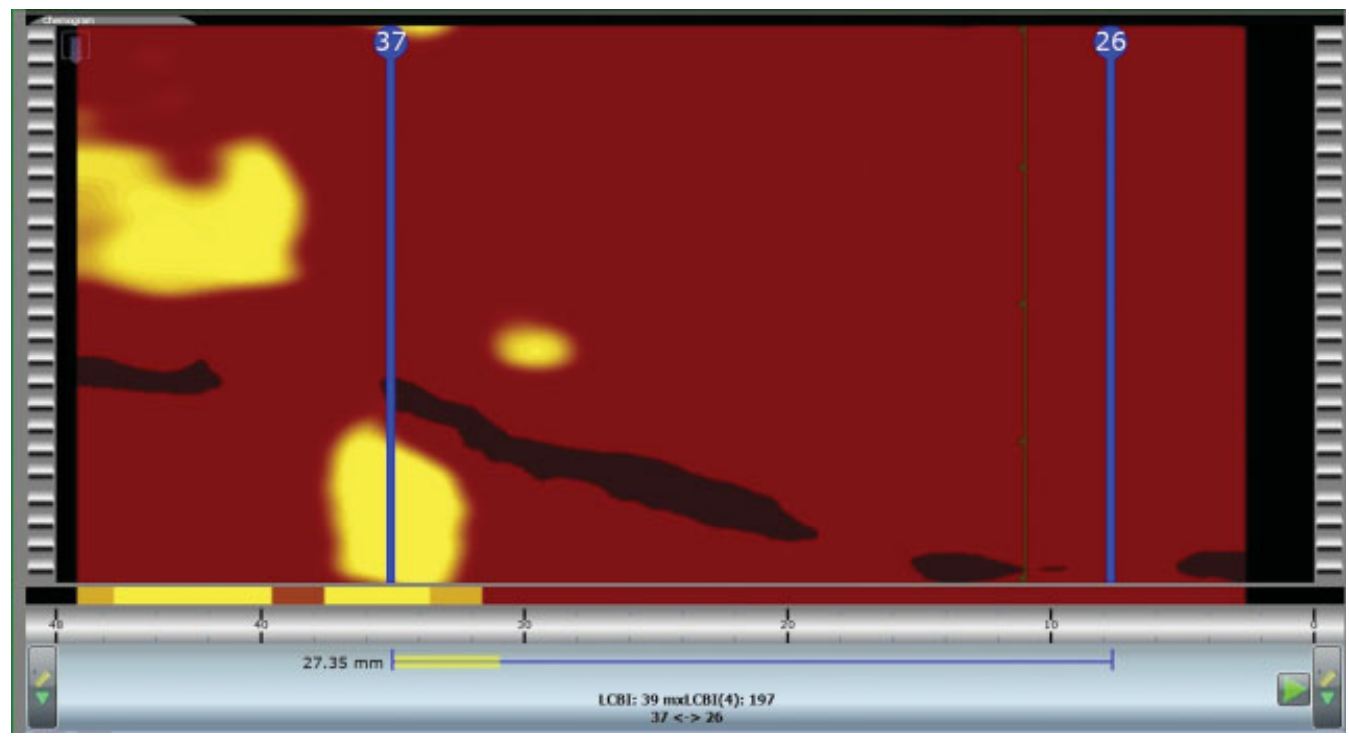

Fig. 3 The near-infrared spectroscopy data are presented as a chemogram. Every pixel of this rectangular color-coded probability map represents the probability of the presence of lipids at a given location. Low probabilities of lipids are depicted as red, while the other extreme of the scale is represented by yellow. The $\mathrm{X}$-axis of the chemogram indicates the pullback position in millimeters, while the $\mathrm{Y}$-axis represents the circumferential position in degrees as though the coronary vessel has been incised along its longitudinal axis. The lipid-core burden index was established to satisfy the need for the quantification of the presence of lipids, defined as the fraction of yellow and red pixels on the chemogram multiplied by one thousand. The maximal lipid core burden index per $4 \mathrm{~mm}$ describes the region with the highest lipid burden.

using different types of embolic protection devices and stents. Interestingly, the CREST study taught us that while younger patients tended to benefit from CAS, older patients profited from CEA. ${ }^{21}$ A possible explanation of this phenomenon might be the more advanced atherosclerosis in older patients, leading to a higher risk of periprocedural stroke during CAS. Many diagnostic methods have been tested for the detection of such high-risk carotid plaques. Some results were obtained with conventional ultrasound. ${ }^{29}$ Promising results were obtained with MRI, where some plaque features such as intraplaque hemorrhage or lipid core were associated with plaque vulnerability. ${ }^{30-33}$ A promising method, given its high spatial resolution and correlation with the histopathology of carotid plaques, is multidetector computed tomography. ${ }^{34,35}$ Because NIRS is an invasive imaging modality, it can be assumed that it will preferably be used in patients already indicated for carotid angiography and/or stenting. In such cases, the risks associated with the procedure will not be dramatically increased. Current knowledge suggests that NIRS could play an important role in the detection of lipid-rich high-risk plaques. Knowledge about the quantity of lipids could play an important role in decisions about the treatment strategy. We hypothesize that CEA might be the preferable treatment strategy in patients with a high lipid burden. Another possible outcome is a stricter approach to embolic protection. Herein, we provide hypotheses for the use of NIRS in carotid interventions based on the current findings from coronary research. It is important to emphasize that these coronary data are mostly from small pioneering studies, and most of the hypotheses must be verified by larger trials. The later mentioned assumptions must therefore be considered cautiously.

\section{Embolic Protection}

As aforementioned, distal embolization of atherosclerotic debris is a major limitation of CAS, and different embolic protection devices have been developed to reduce this risk. Currently, either distal protection with a filter or proximal protection devices are routinely used. ${ }^{36-40}$

As demonstrated in the coronary arteries, NIRS could be very helpful for predicting the distal embolization of the lipid content. Studies have proved that high LCBI is associated with periprocedural MI. ${ }^{41-45}$ The CANARY trial proved that this association could still be observed when a distal protection filter was used. It can be assumed that this knowledge could also be transferred to carotid interventions (CANARY trial, Coronary Assessment by Near-infrared of Atherosclerotic Rupture-prone Yellow, NCT01268319). We recently published the first case report of the use of NIRS in CAS, demonstrating the distal embolization of lipid cores during a filter-protected CAS that was associated with transient neurologic symptoms. ${ }^{46}$ Although we currently do not have any supporting evidence, it can be hypothesized that high LCBI is associated with a greater risk of distal embolization and periprocedural stroke. A weak correlation between plaque composition and new ipsilateral MRI lesions was observed in a small IVUS virtual histology study. ${ }^{47}$ In such cases, NIRS might be used for the risk stratification of patients, either to decide between the types of protection devices used or, in high-risk patients, to switch the strategy to CEA. Obviously, these hypotheses are only speculation and clinical trials are needed to prove them. 


\section{Optimization of Stenting}

Spectroscopy might also be used for the optimization of stent length to cover the whole lesion based on a more precise determination of the extent of the plaque or to decide between the types of stent used. Coronary case studies have documented acute in-stent thrombosis following percutaneous coronary interventions (PCIs) in which the lipid core, imaged by NIRS, was not entirely covered by a stent. ${ }^{48,49}$ A small study by Dixon et al suggested the potential of NIRSIVUS in the optimization of stent length to cover the whole LCP. $^{50}$ Furthermore, a small study by Papayannis et al observed an association between the amount of LCBI and the formation of thrombi after $\mathrm{PCI}$, as determined by optical coherence spectroscopy. $^{51}$

Some data have also suggested that the embolic load during a carotid intervention might vary according to the type of stent used. ${ }^{52}$ The idea here is that whereas the open cell type of stent is less likely to cause kinking of a tortuous vessel, the closed cell type of stent affords fuller coverage of the lesion and thus more effectively prevents distal embolization of the plaque's content. Although other studies have disproved this hypothesis, ${ }^{53}$ closed cell types of stents are indeed used in lesions with suspected high emboligenicity in common practice. If the theory proves to be true, decision making about the type of stent used might be another important use of NIRS.

\section{The Role of NIRS-IVUS in the Risk Stratification of Patients}

Although the research into the management of carotid artery disease has already passed several important milestones, the indications for revascularization in asymptomatic patients remain uncertain. The relative benefit of invasive revascularization over modern complex medical therapy, paired with smoking cessation programs, remains unclear. ${ }^{20,54}$ Most of the evidences on which we base our decisions were obtained before the introduction of modern drugs. It is essential to identify a subgroup of patients at higher risk for stroke that will benefit from revascularization and subsequently to choose the most suitable and safest form of revascularization.

The intention behind the development of NIRS was to identify the so-called vulnerable atherosclerotic plaques. These lesions supposedly bear a greater risk of causing a carotid event. Thus, the identification of such plaques in vivo might be essential for the risk stratification of patients to either medical therapy or one of the types of revascularization.

Current research in the field of NIRS is focused in this direction. From coronary research, we have learned that lesions responsible for acute coronary syndrome more often harbor lipid core plaques ${ }^{55}$ and that the lesions responsible for ST-elevation MI can be characterized by a certain threshold of LCBI. ${ }^{56}$ A small, pioneering prospective trial recently found that the amount of LCBI was correlated with the incidence of major cardiovascular events (the composite of all-cause mortality, nonfatal ACS, stroke, and unplanned coronary revascularization). ${ }^{57}$ Much larger prospective coronary studies are already in the process of patient recruitment, and they are expected to yield results in a few years. Obviously, it might be difficult to transfer the knowledge learned in the coronary studies to the carotid arteries if we consider the different pathophysiologies of acute events in the different vascular beds. Most carotid events are caused by embolisms, while acute coronary events are usually caused by the rupture of lipid-rich vulnerable plaques. The information might thus be untransferable.

Once we decide that revascularization is the more beneficial option, a decision between CAS and CEA remains to be made. Obviously, patients with many internal comorbidities who are at high risk for surgical complications or who have different attitudes about surgery will probably benefit from the less invasive CAS, as we also can assume from the results of the SAPHIRE trial. ${ }^{16}$ In contrast, patients with lipid-laden plaques have a higher risk of periprocedural stroke. ${ }^{20,21}$ These patients will probably benefit from CEA. In such cases, NIRS could provide important insights.

\section{Conclusion}

Carotid artery disease is a major cause of morbidity and mortality, and its treatment plays an important role in the prevention of stroke. Current guidelines for the management of the disease contain many possible flaws because they are partly based on outdated evidence and do not emphasize the pathophysiology of the disease. Near-infrared spectroscopy paired with IVUS might provide important information about the anatomy and composition of an atherosclerotic plaque, and this information could play a crucial role in the management of carotid artery disease in the near future. The authors of this review have outlined a few possible applications of NIRS in the coronary arteries, ranging from the more conceivable utilization in the optimization of CAS to prevent periprocedural stroke to a less probable role in the risk stratification of asymptomatic patients. However, it is important to emphasize that all of these speculations are based on the first pieces of information that were obtained from coronary artery research. No evidence is currently available for the utility of NIRS in carotid arteries.

\section{Summary}

Carotid artery disease is a major cause of morbidity and mortality, and its treatment serves an important role in the prevention of stroke. Current guidelines on the management of the disease contain many flaws because they are partly based on outdated evidence. Near-infrared spectroscopy is a novel diagnostic method that could be useful for the improvement of the management of carotid atherosclerosis by providing more thorough information about the underlying carotid plaque. Currently, we are only at the beginning of research in this field, and solid evidence is lacking. It seems plausible that better risk stratification of patients based on the information provided by NIRS and IVUS might decrease the incidence of adverse events during the invasive treatment of carotid artery disease. 


\section{Note}

The authors declare that they have no commercial, proprietary, or financial interests in any products or companies described in this article.

\section{Acknowledgments}

This article was supported by $\mathrm{MH}$ CZ-DRO, University Hospital Motol, Prague, Czech Republic 00064203 and by SVV-2013-266509 from the Charles University in Prague.

\section{References}

1 Brott TG, Halperin JL, Abbara S, Bacharach JM, Barr JD, Bush RL, Cates CU, Creager MA, Fowler SB, Friday G, Hertzberg VS, McIff EB, Moore WS, Panagos PD, Riles TS, Rosenwasser RH, Taylor AJ; American College of Cardiology Foundation/American Heart Association Task Force on Practice Guidelines; American Stroke Assocation; American Association of Neuroscience Nurses; American Association of Neurological Surgeons; American College of Radiology; American Society of Neuroradiology; Congress of Neurolgocial Surgeons; Society of Atherosclerosis Imaging and Prevention; Society for Cardiovascular Angiography and Interventions; Society of Interventional Radiology; Society of NeuroInterventional Surgery; Society for Vascular Medicine; Society for Vascular Surgery; American Academy of Neurology and Society of Cardiovascular Computed Tomography.2011 ASA/ACCF/AHA/ AANN/AANS/ACR/ASNR/CNS/SAIP/SCAI/SIR/SNIS/SVM/SVS guideline on the management of patients with extracranial carotid and vertebral artery disease. Stroke 2011;42(8):e464-540

2 Tendera M, Aboyans V, Bartelink ML, et al; European Stroke Organisation; ESC Committee for Practice Guidelines. ESC Guidelines on the diagnosis and treatment of peripheral artery diseases: Document covering atherosclerotic disease of extracranial carotid and vertebral, mesenteric, renal, upper and lower extremity arteries: the Task Force on the Diagnosis and Treatment of Peripheral Artery Diseases of the European Society of Cardiology (ESC). Eur Heart J 2011;32(22):2851-2906

3 Donnan GA, Fisher M, Macleod M, Davis SM. Stroke. Lancet 2008; 371(9624):1612-1623

4 Sacco RL, Kargman DE, Gu Q, Zamanillo MC. Race-ethnicity and determinants of intracranial atherosclerotic cerebral infarction. The Northern Manhattan Stroke Study. Stroke 1995;26(1):14-20

5 Barnett HJ, Gunton RW, Eliasziw M, et al. Causes and severity of ischemic stroke in patients with internal carotid artery stenosis. JAMA 2000;283(11):1429-1436

6 Inzitari D, Eliasziw M, Gates P, et al. The causes and risk of stroke in patients with asymptomatic internal-carotid-artery stenosis. North American Symptomatic Carotid Endarterectomy Trial Collaborators. N Engl J Med 2000;342(23):1693-1700

7 DeBakey ME. Carotid endarterectomy revisited. J Endovasc Surg 1996;3(1):4

8 Eastcott HH, Pickering GW, Rob CG. Reconstruction of internal carotid artery in a patient with intermittent attacks of hemiplegia. Lancet 1954;267(6846):994-996

9 Mathias K. Perkutane transluminale Katheterbehandlung supraaortaler Arterienobstruktionen. Angiology 1981;3:47-50

10 Roubin GS, Yadav S, Iyer SS, Vitek J. Carotid stent-supported angioplasty: a neurovascular intervention to prevent stroke. Am J Cardiol 1996;78(3A):8-12

11 Ferguson GG, Eliasziw M, Barr HWK, et al; North American Symptomatic Carotid Endarterectomy Trial Collaborators. Beneficial effect of carotid endarterectomy in symptomatic patients with high-grade carotid stenosis. N Engl J Med 1991;325(7): 445-453
12 Randomised trial of endarterectomy for recently symptomatic carotid stenosis: final results of the MRC European Carotid Surgery Trial (ECST). Lancet 1998;351(9113):1379-1387

13 Walker MD, Marler JR, Goldstein M, et al. Executive Committee for the Asymptomatic Carotid Atherosclerosis Study. Endarterectomy for asymptomatic carotid artery stenosis. J Am Med Assoc 1995; 273(18):1421-1428

14 Rothwell PM, Goldstein LB. Carotid endarterectomy for asymptomatic carotid stenosis: asymptomatic carotid surgery trial. Stroke 2004;35(10):2425-2427

15 Halliday AW, Thomas D, Mansfield A; Steering Committee. The Asymptomatic Carotid Surgery Trial (ACST). Rationale and design. Eur J Vasc Surg 1994;8(6):703-710

16 Gurm HS, Yadav JS, Fayad P, et al; SAPPHIRE Investigators. Longterm results of carotid stenting versus endarterectomy in highrisk patients. N Engl J Med 2008;358(15):1572-1579

17 Mas JL, Chatellier G, Beyssen B, et al; EVA-3S Investigators. Endarterectomy versus stenting in patients with symptomatic severe carotid stenosis. N Engl J Med 2006;355(16):1660-1671

18 Ringleb PA, Allenberg J, Brückmann $\mathrm{H}$, et al; SPACE Collaborative Group. 30 day results from the SPACE trial of stent-protected angioplasty versus carotid endarterectomy in symptomatic patients: a randomised non-inferiority trial. Lancet 2006;368(9543): 1239-1247

19 Ederle J, Dobson J, Featherstone RL, et al; International Carotid Stenting Study investigators. Carotid artery stenting compared with endarterectomy in patients with symptomatic carotid stenosis (International Carotid Stenting Study): an interim analysis of a randomised controlled trial. Lancet 2010;375(9719):985-997

20 White CJ. Carotid artery stenting. J Am Coll Cardiol 2014;64(7): 722-731

21 Brott TG, Hobson RW II, Howard G, et al; CREST Investigators. Stenting versus endarterectomy for treatment of carotid-artery stenosis. N Engl J Med 2010;363(1):11-23

22 Gardner CM, Tan H, Hull EL, et al. Detection of lipid core coronary plaques in autopsy specimens with a novel catheter-based nearinfrared spectroscopy system. JACC Cardiovasc Imaging 2008;1(5): 638-648

23 Cassis LA, Lodder RA. Near-IR imaging of atheromas in living arterial tissue. Anal Chem 1993;65(9):1247-1256

24 Waxman S, Dixon SR, L'Allier P, et al. In vivo validation of a catheterbased near-infrared spectroscopy system for detection of lipid core coronary plaques: initial results of the SPECTACL study. JACC Cardiovasc Imaging 2009;2(7):858-868

$25 \mathrm{PuJ}$, Mintz GS, Brilakis ES, et al. In vivo characterization of coronary plaques: novel findings from comparing greyscale and virtual histology intravascular ultrasound and near-infrared spectroscopy. Eur Heart J 2012;33(3):372-383

26 Horváth M, Hájek P, Štěchovsky C, Veselka J. Vulnerable plaque imaging and acute coronary syndrome. Cor Vasa 2014;56: e362-e368

27 Stěchovský C, Horváth M, Hájek P, Veselka J. Detection of vulnerable atherosclerotic plaque with near-infrared spectroscopy: a systematic review [in Czech]. Vnitr Lek 2014;60(4):375-379

28 Schnaudigel S, Gröschel K, Pilgram SM, Kastrup A. New brain lesions after carotid stenting versus carotid endarterectomy: a systematic review of the literature. Stroke 2008;39(6): 1911-1919

29 Biasi GM, Froio A, Diethrich EB, et al. Carotid plaque echolucency increases the risk of stroke in carotid stenting: the Imaging in Carotid Angioplasty and Risk of Stroke (ICAROS) study. Circulation 2004;110(6):756-762

30 Yamada K, Kawasaki M, Yoshimura S, et al. Prediction of silent ischemic lesions after carotid artery stenting using integrated backscatter ultrasound and magnetic resonance imaging. Atherosclerosis 2010;208(1):161-166

31 van den Bouwhuijsen QJ, Vernooij MW, Hofman A, Krestin GP, van der Lugt A, Witteman JC. Determinants of magnetic resonance 
imaging detected carotid plaque components: the Rotterdam Study. Eur Heart J 2012;33(2):221-229

32 Millon A, Mathevet JL, Boussel L, et al. High-resolution magnetic resonance imaging of carotid atherosclerosis identifies vulnerable carotid plaques. J Vasc Surg 2013;57(4):1046-1051.e2

33 Saam T, Hetterich H, Hoffmann V, et al. Meta-analysis and systematic review of the predictive value of carotid plaque hemorrhage on cerebrovascular events by magnetic resonance imaging. J Am Coll Cardiol 2013;62(12):1081-1091

34 Uchiyama N, Misaki K, Mohri M, et al. Association between carotid plaque composition assessed by multidetector computed tomography and cerebral embolism after carotid stenting. Neuroradiology 2012;54(5):487-493

35 de Weert TT, Ouhlous M, Meijering E, et al. In vivo characterization and quantification of atherosclerotic carotid plaque components with multidetector computed tomography and histopathological correlation. Arterioscler Thromb Vasc Biol 2006;26(10): 2366-2372

36 Spacek M, Veselka J. Carotid artery stenting - current status of the procedure. Arch Med Sci 2013;9(6):1028-1034

37 Kastrup A, Gröschel K, Krapf H, Brehm BR, Dichgans J, Schulz JB. Early outcome of carotid angioplasty and stenting with and without cerebral protection devices: a systematic review of the literature. Stroke 2003;34(3):813-819

38 Clair DG, Hopkins LN, Mehta M, et al; EMPiRE Clinical Study Investigators. Neuroprotection during carotid artery stenting using the GORE flow reversal system: 30-day outcomes in the EMPiRE Clinical Study. Catheter Cardiovasc Interv 2011;77(3): 420-429

39 Parodi JC, Schönholz C, Parodi FE, Sicard G, Ferreira LM. Initial 200 cases of carotid artery stenting using a reversal-of-flow cerebral protection device. J Cardiovasc Surg (Torino) 2007; 48(2):117-124

40 Bijuklic K, Wandler A, Hazizi F, Schofer J. The PROFI study (Prevention of Cerebral Embolization by Proximal Balloon Occlusion Compared to Filter Protection During Carotid Artery Stenting): a prospective randomized trial. J Am Coll Cardiol 2012;59(15): 1383-1389

41 Raghunathan D, Abdel-Karim AR, Papayannis AC, et al. Relation between the presence and extent of coronary lipid core plaques detected by near-infrared spectroscopy with postpercutaneous coronary intervention myocardial infarction. Am J Cardiol 2011; 107(11):1613-1618

42 Schultz CJ, Serruys PW, van der Ent M, et al. First-in-man clinical use of combined near-infrared spectroscopy and intravascular ultrasound: a potential key to predict distal embolization and no-reflow? J Am Coll Cardiol 2010;56(4):314

43 Goldstein JA, Maini B, Dixon SR, et al. Detection of lipid-core plaques by intracoronary near-infrared spectroscopy identifies high risk of periprocedural myocardial infarction. Circ Cardiovasc Interv 2011;4(5):429-437

44 Goldstein JA, Grines C, Fischell T, et al. Coronary embolization following balloon dilation of lipid-core plaques. JACC Cardiovasc Imaging 2009;2(12):1420-1424

45 Saeed B, Banerjee S, Brilakis ES. Slow flow after stenting of a coronary lesion with a large lipid core plaque detected by nearinfrared spectroscopy. EuroIntervention 2010;6(4):545

46 Horváth M, Hájek P, Muller JE, et al. First-in-man near-infrared spectroscopy proof of lipid-core embolization during carotid artery stenting. Arch Med Sci 2014; In press

47 Timaran CH, Rosero EB, Martinez AE, Ilarraza A, Modrall JG, Clagett GP. Atherosclerotic plaque composition assessed by virtual histology intravascular ultrasound and cerebral embolization after carotid stenting. J Vasc Surg 2010;52(5):1188-1194

48 Sakhuja R, Suh WM, Jaffer FA, Jang IK. Residual thrombogenic substrate after rupture of a lipid-rich plaque: possible mechanism of acute stent thrombosis? Circulation 2010;122(22):2349-2350

49 Stouffer GA. The Use of Near-Infrared Spectroscopy to Optimize Stent Length. J Invasive Cardiol 2013;25:19A

50 Dixon SR, Grines CL, Munir A, et al. Analysis of target lesion length before coronary artery stenting using angiography and nearinfrared spectroscopy versus angiography alone. Am J Cardiol 2012;109(1):60-66

51 Papayannis AC, Abdel-Karim AR, Mahmood A, et al. Association of coronary lipid core plaque with intrastent thrombus formation: a near-infrared spectroscopy and optical coherence tomography study. Catheter Cardiovasc Interv 2013;81(3):488-493

52 Bosiers M, de Donato G, Deloose K, et al. Does free cell area influence the outcome in carotid artery stenting? Eur J Vasc Endovasc Surg 2007;33(2):135-141, discussion 142-143

53 Schillinger M, Gschwendtner M, Reimers B, et al. Does carotid stent cell design matter? Stroke 2008;39(3):905-909

54 Abbott AL. Medical (nonsurgical) intervention alone is now best for prevention of stroke associated with asymptomatic severe carotid stenosis: results of a systematic review and analysis. Stroke 2009;40(10):e573-e583

55 Madder RD, Smith JL, Dixon SR, Goldstein JA. Composition of target lesions by near-infrared spectroscopy in patients with acute coronary syndrome versus stable angina. Circ Cardiovasc Interv 2012;5(1):55-61

56 Madder RD, Goldstein JA, Madden SP, et al. Detection by nearinfrared spectroscopy of large lipid core plaques at culprit sites in patients with acute ST-segment elevation myocardial infarction. JACC Cardiovasc Interv 2013;6(8):838-846

57 Oemrawsingh RM, Cheng JM, García-García HM, et al; ATHEROREMO-NIRS Investigators. Near-infrared spectroscopy predicts cardiovascular outcome in patients with coronary artery disease. J Am Coll Cardiol 2014;64(23):2510-2518 